\title{
Occurrence and Seasonal Variation of Microplastics in the Effluent from Wastewater Treatment Plants in Qingdao, China
}

\author{
Fenghua Jiang, Menghui Wang, Jinfeng Ding, Wei Cao and Chengjun Sun * $\mathbb{D}$
}

Citation: Jiang, F.; Wang, M.; Ding, J.; Cao, W.; Sun, C. Occurrence and Seasonal Variation of Microplastics in the Effluent from Wastewater Treatment Plants in Qingdao, China. J. Mar. Sci. Eng. 2022, 10, 58. https:// doi.org/10.3390/jmse10010058

Academic Editor: Ana

Marta Gonçalves

Received: 29 November 2021

Accepted: 30 December 2021

Published: 4 January 2022

Publisher's Note: MDPI stays neutral with regard to jurisdictional claims in published maps and institutional affiliations.

Copyright: (c) 2022 by the authors. Licensee MDPI, Basel, Switzerland. This article is an open access article distributed under the terms and conditions of the Creative Commons Attribution (CC BY) license (https:// creativecommons.org/licenses/by/ $4.0 /)$.

\author{
Key Laboratory of Marine Eco-Environmental Science and Technology, Marine Bioresource and \\ Environment Research Center, First Institute of Oceanography, Ministry of Natural Resources (MNR), \\ Qingdao 266061, China; jiangfh@fio.org.cn (F.J.); 15621492291@163.com (M.W.); \\ dingjf1004@gmail.com (J.D.); caowei@fio.org.cn (W.C.) \\ * Correspondence: csun@fio.org.cn
}

\begin{abstract}
Wastewater treatment plants (WWTPs) are considered as one of the important sources of microplastics (MPs) in the marine environment. In this paper, the characteristics of MPs in the effluent discharged from five WWTPs in Qingdao, China, in winter and summer were analyzed. The results showed that only fibers and fragments were observed, with fibers as a dominant part. Rayon was the most domain polymer type, followed by Polyethylene terephthalate (PET) and chlorinated polyethylene (CPE). The average sizes of fiber MPs were $1010 \pm 924 \mu \mathrm{m}$ and $610 \pm 691 \mu \mathrm{m}$ in winter and summer, respectively. The contents of rayon were higher in summer than in winter. More small and transparent MPs were observed in summer. Rayon abundances ranged from 4.1 to 19.9 items/L and 33.3 to 116.7 items/L, with $12.3 \pm 5.6$ items/L and $67.6 \pm 30.6$ items/L as the average value in winter and in summer, respectively. The abundances of other polymer type MPs were 7.23 19.65 items/ $\mathrm{L}$ with average value of $12.7 \pm 4.7$ items $/ \mathrm{L}$ in winter and 12.0 20.0 items/L with $16.8 \pm 4.7$ items $/ \mathrm{L}$ in summer. The daily emissions were estimated as $8.38 \times 10^{9} \sim 4.25 \times 10^{10}$ items $(9.2 \sim 27.8 \mathrm{~kg})$ for rayon and $8.0 \times 10^{9} \sim 1.2 \times 10^{10}$ items $(7.6 \sim 5.3 \mathrm{~kg})$ discharged for the other polymer type MPs from the five WWTPs. The results indicated that the seasonal variation of characteristics and emission of MPs in the effluent from WWTPs was mainly caused by increasing discharge of rayon, which may relate to people's living habits and tourism activities.
\end{abstract}

Keywords: microplastics; characteristic; wastewater treatment plant; effluent

\section{Introduction}

Microplastics (MPs, $<5 \mathrm{~mm}$ ), as a new type of pollutants on a global scale, have attracted growing attention and have become one of the popular research areas in recent years [1]. MPs have become ubiquitous in the environment and have been observed in the atmosphere [2], soil [3], lakes and rivers [4,5], the remote ocean in the Arctic [6] and Antarctica area [7], and even in the deep-sea sediments [8] and living organisms [9]. MPs in the environment originate from primary or secondary sources. Primary MPs are produced as microscopic-sized pellets and directly used in a wide range of applications, such as exfoliating frosted microbeads in cosmetics or raw pellets in industrial production. Secondary MPs are fragmented from large-sized plastics due to physical and chemical actions in the environment [10]. Due to the similar size range of MPs to that of the prey of many marine organisms, MPs tend to be ingested by a wide range of biota in benthic and pelagic ecosystems' organism [11]. MPs ingested by aquatic organisms can affect their behavior, feeding, growth, and reproduction [11]. MPs, containing additives during the polymer synthesis, also adsorb chemical pollutants directly from surrounding environments [12]. Thus, they may play an important role not only during the transportation process of pollutants in the environment but also in the transfer and bioaccumulation processes within the food web, resulting in many environmental problems [13]. Moreover, MPs from contaminated drinking water [14] and aquatic products [15] will pose a potential threat to human health. 
Wastewater treatment plants (WWTPs) are designed to collect and treat various types of domestic or industrial wastewater, which are considered as one of the significant point sources discharging MPs into the environment and have gained more attention during recent years [16-19]. Microfibers from clothes washing and microbeads from cosmetics and cleaning agents are carried with wastewater via sewers and later discharged into the environments with effluents from WWTPs. Large numbers of fibers are discharged into wastewater during the washing process of clothes and synthetic garments [20,21]. About 4594 94,500 microbeads could be released in a single use of facial scrubs [22]. Microbeads are of little concern due to the ban of microbeads' production and usage. Most MPs in the wastewater are removed during the treatment process [16-18,23,24]. Although WWTPs are very effective in removing MPs, the amount of MPs discharged from WWTPs is still huge due to the tremendous daily treatment capacities $[16,18,19]$. Since MPs with smaller size tend to escape when sampled with different sizes of stainless steel sieves, the amount of MPs discharged from WWTPs might be underestimated. Additionally, the investigations sampled in one season have not considered the changes or differences between different seasons. This also causes indeterminacy in estimating the amount of MPs discharged from WWTPs.

In the last few years, the abundance, characteristics, transfer, and removal of MPs from WWTPs in several cities in China, such as Xiamen, Beijing, Xi'an, and Guilin, were investigated using various sampling methods, with removal rates of MPs ranging from $63 \%$ to $99 \%$ [18,23-25]. Due to a lack of a unified sampling approach, it is difficult to compare results from different WWTPs. To our knowledge, there are no reports about the occurrence of MPs from WWTPs in Qingdao, China. This study aimed to investigate the characteristics and abundance in the effluent from five WWTPs in Qingdao, and their differences in summer and winter were compared. Furthermore, MPs discharging into nearshore area were estimated.

\section{Materials and Methods}

\subsection{Sampling Sites}

Qingdao is a typical coastal city located in the north of China (Figure 1), and also famous as an important harbor city and a tourist destination. There were a total of 2.74 million people in the central city in 2019. There are seven WWTPs handling domestic wastewater generated in daily life and industrial wastewater. Most water has been preliminarily treated in the industrial plants. The effluents of WWTPs are discharged into the nearshore area of Qingdao, including the Jiaozhou Bay and the Yellow sea. In recent years, the percent of industrial wastewater has decreased with the emigration of industrial plants from the central city.

\subsection{Sampling and Pretreatment}

Effluent samples were collected from five of the seven WWTPs in the Qingdao urban area, China, in November 2018 and July 2019. The designed capacities for each WWTP are $1.7 \times 10^{5} \mathrm{~m}^{3} / \mathrm{d}, 0.8 \times 10^{5} \mathrm{~m}^{3} / \mathrm{d}, 1.6 \times 10^{5} \mathrm{~m}^{3} / \mathrm{d}, 1.0 \times 10^{5} \mathrm{~m}^{3} / \mathrm{d}$, and $1.4 \times 10^{5} \mathrm{~m}^{3} / \mathrm{d}$ for $\mathrm{W} 1 \sim \mathrm{W} 5$, respectively. The influent of wastewater to $\mathrm{W} 1$ and $\mathrm{W} 2$ include both industrial wastewater and domestic sewage. Domestic sewage is the main source of W3 W5. The effluent from $\mathrm{W} 1 \sim \mathrm{W} 4$ is discharged into Jiaozhou Bay, which is connected to the Yellow Sew, while the effluent from W5 is discharged into Yellow Sea area directly, as shown in Figure 1.

Sampling was conducted every $2 \mathrm{~h}$ by an auto-sampling device (Sigma SD900, Hach, Loveland, USA) for a duration of $24 \mathrm{~h}$, and the collected wastewater in 12 bottles was mixed thoroughly in one large bottle. About $500 \mathrm{~mL}$ of the mixture of effluent sample collected with the glass bottles in $24 \mathrm{~h}$ was considered as one sample. Triplicate samples (about $1500 \mathrm{~mL}$ as the total volume) were collected from each WWTP. The samples were filtered through a $0.45-\mu \mathrm{m}$-pore size nitrocellulose membrane (50-mm diameter, Shanghai Xingya, China) with a vacuum pump (SHB-IIIA, Zhengzhou, China). To reduce the deviation 
caused by operation procedures, the accurate volume of the water sample was measured after filtration. Then, the inner wall of the sampling bottle and the filter device (Solvent filter, Jinteng Technology, Tianjin, China) were rinsed completely with ultrapure water (Unique-R 20, RSJ, Xiamen, China) and filtered with the same membrane. The filter membrane was sealed in clean petri dishes with parafilm and stored at $4{ }^{\circ} \mathrm{C}$ before further analysis.

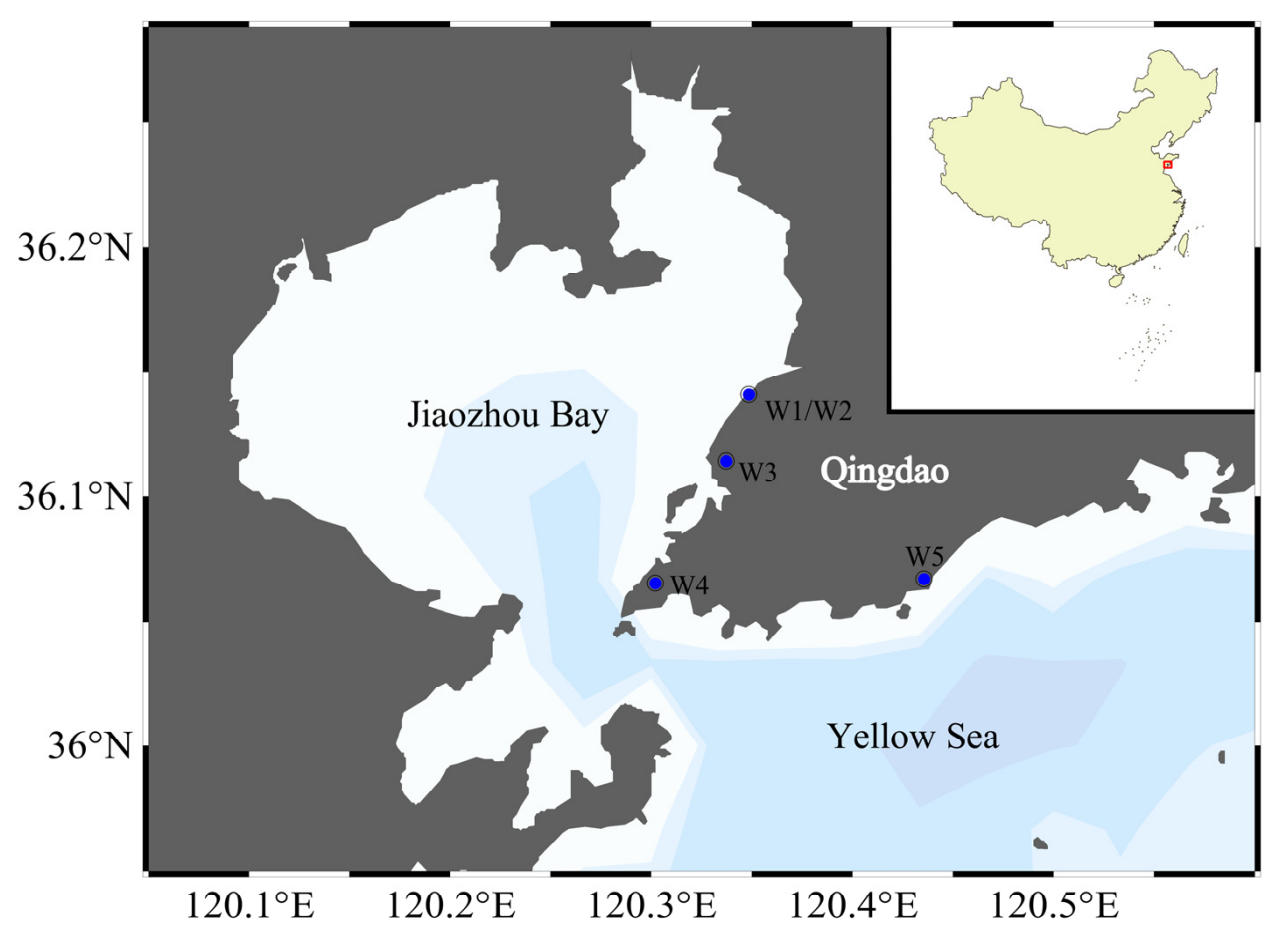

Figure 1. Sampling site in Qingdao, China.

\subsection{Observation and Identification of MPs}

The membrane samples were observed under a stereo-microscope (Nikon SMZ1270, Tokyo, Japan) with a magnification of 30 80 times. Images of MPs were obtained using a Nikon Ds-Ri2 digital camera system, which was attached to the stereo-microscope. The suspected MPs were labeled using a pen in the vision of the stereo-microscope. The size of MPs was measured with the instrument in the microscope system. The shape, size, and color were all recorded. For fragments and films, length and width were recorded. The labeled particles were identified with micro-Fourier transform Infrared Spectroscopy in Attenuated Total Reflection model (ATR- $\mu$-FTIR, Perkin-Elmer Spotlight 400, Llantrisant, UK) equipped with a germanium crystal. The range of spectrum was from $4000 \mathrm{~cm}^{-1}$ to $750 \mathrm{~cm}^{-1}$ with $16 \mathrm{~cm}^{-1}$ for resolution. The pixel size was set as $6.25 \mathrm{~cm}^{-1}$. Sample acquisition time was $3 \mathrm{~s}$ and 16 co-scans were performed for each measurement. The polymer type was confirmed by comparing the obtained spectra with the Sadtler Library and the match coefficient was greater than $80 \%$. The polymer was classified as fiber, fragment, film, foam, granular, and sphere according to the shape. Considering a 330- $\mu \mathrm{m}$ pore size of a trawling net is usually used when collecting MPs from surface seawater, $330 \mu \mathrm{m}$ was added in the size subgroup division. Thus, the MPs were divided into eight groups of the following size ranges: $<100 \mu \mathrm{m}, 100 \sim 330 \mu \mathrm{m}, 330 \sim 500 \mu \mathrm{m}, 500 \sim 1000 \mu \mathrm{m}$, 1000 2000 $\mu \mathrm{m}, 2000 \sim 3000 \mu \mathrm{m}, 3000 \sim 4000 \mu \mathrm{m}$, and 4000 5000 $\mu \mathrm{m}$, according to their sizes.

\subsection{Contamination Control}

Precautions were taken during the whole experiment process to avoid contamination. Cotton laboratory coats and nitrile gloves were always worn during the sample collection, separation, and pretreatment processes. Glass bottles, non-plastic containers, and tools were used at all times when possible and rinsed completely with Mill-Q water. The reservoir 
of the filtration device was always covered with aluminum foil when filtering to avoid potential air contamination. The wastewater sample was replaced with Mill-Q water to filter with the nitrocellulose membrane, filtering $500 \mathrm{~mL}$ of Mill-Q water as the same process of the sample pretreatment, which was the blank control. There were no MPs found on the control filter.

\subsection{Data Analysis}

MPs' abundance in the effluent of WWTPs is expressed as the number of MPs' particles per liter of water (unit: items/L). Data analysis was performed using Microsoft Excel 2016 and Origin 8.5. The differences in MPs' abundances between two seasons were tested (One-Sample Kolmogorov-Smirnov Test, Levene's Test for Equality of Variances, t-test for Equality of Means) using SPSS 26.0.

\subsection{Assessment of MPs Discharged from WWTPs}

The amount of MPs discharged from WWTPs was assessed based on the abundance of MPs in the effluent of each WWTP and their daily treatment capacity. Combined with polymers' types and their densities, the average size and the mass of MPs discharged with the effluent from the five WWTPs in Qingdao into Jiaozhou Bay and Yellow Sea were estimated.

\section{Results}

\subsection{Characteristics of MPs in the Effluent of WWTPs}

A total of 1337 suspected particles were analyzed using $\mu$-FT-IR in the effluent from the five WWTPs and 891 particles (about $66.6 \%$ of suspected particles) were identified as MPs, in which 639 particles were rayon. As for different seasons, 581 and 756 suspected particles in the effluent in winter and summer, and 258 and 633 particles were identified as MPs, with 132 and 507 items as rayon, respectively. The morphotypes and polymer types of MPs are shown in Figure 2. The $\mu$-FT-IR results indicated that the main polymer types were rayon, polyethylene terephthalate (PET,) and chlorinated polyethylene (CPE). More than $95 \%$ of the MPs were fibers. MPs smaller than $1000 \mu \mathrm{m}$ comprised $80.0 \%$ of the total MPs. The dominant colors were transparent, blue, and black, accounting for $56.9 \%, 20.2 \%$, and $14.1 \%$ of the total MPs, respectively.

Figure 3 show MPs' characteristics in the effluent from WWTPs in this study. It can be seen that fibers accounted for $99.2 \%$ and $94.3 \%$ of the total MPs in the effluent in winter and summer, respectively (Figure 3a). Only two (0.8\%) fragment MPs were found in the effluent in the winter sample and $36(5.7 \%)$ fragment MPs were found in the summer sample. No microbeads or foam was found. Fragments were more often observed in summer than in winter.

There were 15 kinds of polymers observed in the effluent in both the winter and summer samples. Figure $3 \mathrm{~b}$ shows that rayon was the most dominant polymer in the effluent in both winter and summer, followed by PET and CPE polymers. The three main polymer types accounted for $84.1 \%$ (Rayon $51.2 \%$, PET $17.1 \%$, CPE $15.9 \%$ ) of all MPs in the effluent in winter and $89.4 \%$ (Rayon $80.1 \%$, PET $7.1 \%$, CPE $2.2 \%$ ) in summer. The percentage of rayon was lower in winter than in summer, while those of PET and CPE were higher in winter than in summer. Other polymers, e.g., poly vinylidene chloride (PVDC), polyacrylamids (PAM), polypropylene (PP), Polystyrene (PS), Poly (vinylidene fluoride) (PVDF), polyvinyl alcohol (PVA), nylon, Polyvinyl chloride (PVC), and polyethene (PE), were all observed in the effluent in both winter and summer samples. Ethylene carbonate (EC), polybutylene terephthalate (PBT), and polyphenylenesulfide (PPS) were found only in the effluent in winter, while acrylic, poly caprolactone (PCL), and poly (ethylene imine) (PEI) were found only in the effluent in summer. 


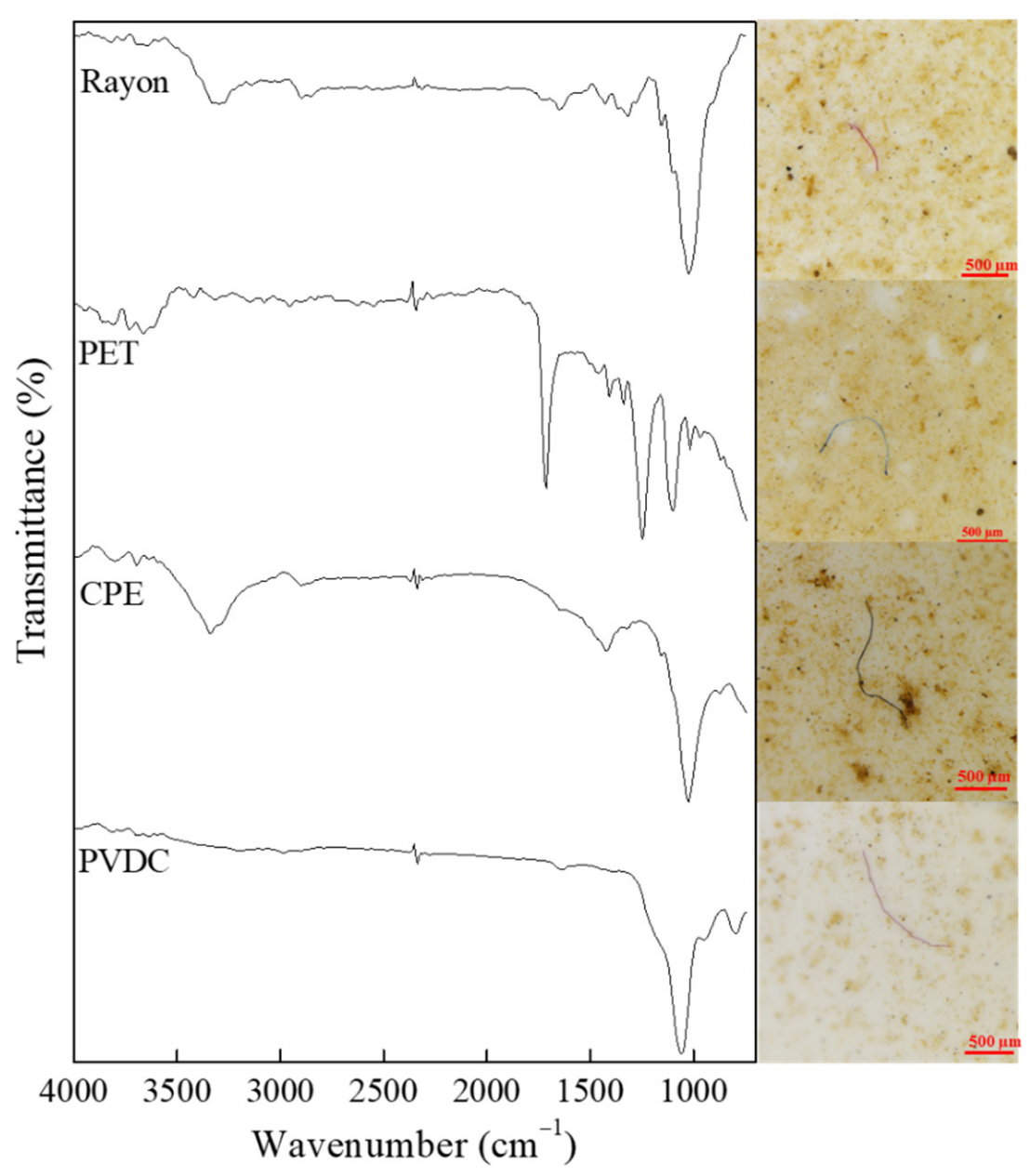

Figure 2. The $\mu$ - FT-IR spectra of major MP polymers (Rayon, PET, CPE, and PVDC) found in the effluents from WWTPs (left). Typical morphotypes of MP particles observed in the effluents from WWTPs in Qingdao (right).

The size distribution of MPs in the effluent from WWTPs in winter and summer is shown in Figure 3c. The observed MPs were divided into eight ranges. It can be seen that MPs in the size of 500 1000 $\mu \mathrm{m}$ were the most abundant part (31.0\%) in winter, followed by those in the size of 1000 2000 $\mu \mathrm{m}(22.9 \%), 330 \sim 500 \mu \mathrm{m}(19.4 \%)$, and 100 330 $\mu \mathrm{m}(15.9 \%)$, while in summer, the most abundant MPs were in the size range of 100 330 $\mu \mathrm{m}$, occupying $37.9 \%$ of all the MPs. Those in the size range of 500 1000 $\mu \mathrm{m}$ decreased to $28.8 \%$. The percentages of MPs in the size of 330 500 $\mu \mathrm{m}$ and 1000 2000 $\mu \mathrm{m}$ were decreased to $16.1 \%$ and $10.0 \%$. The proportions smaller than $1000 \mu \mathrm{m}$ and $<2000 \mu \mathrm{m}$ were $66.7 \%$ and $89.6 \%$ in the MPs in effluent from WWTPs in winter, respectively, while the values changed to $85.5 \%$ and $95.5 \%$ in summer. The average sizes of MPs were $1010 \pm 924 \mu \mathrm{m}$ and $610 \pm 591 \mu \mathrm{m}$ in winter and summer, respectively.

Nine colors of MPs were observed in the effluent from WWTPs both in winter and summer, including the transparent, black, blue, red, green, gray, purple, white, and yellow. Among them, blue MPs accounted for 38.4\% and were the most abundant MPs in winter, followed by transparent and black MPs, with the percentages of $29.7 \%$ and $21.7 \%$, respectively (Figure 3d). Transparent MPs accounted for $68.2 \%$ of the MPs in summer, and blue and black MPs were $12.8 \%$ and $11.06 \%$, respectively. The abundances of red, green, gray, purple, white, and yellow occupied 10.9\% (26 items) and 7.9\% (50 items) of the total MPs in winter and summer, respectively. 
(a) Shape

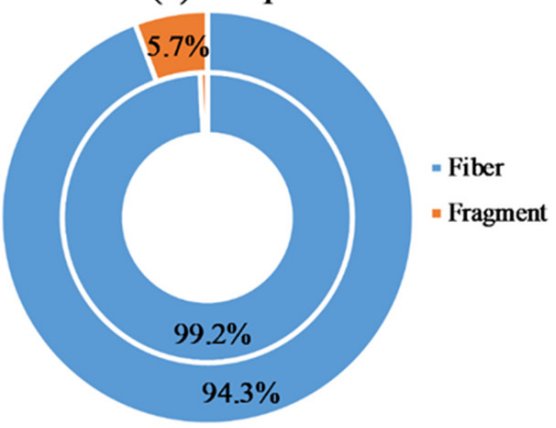

(c) size

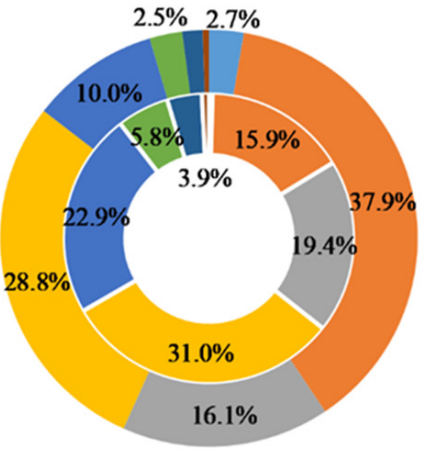

(b) Polymer type

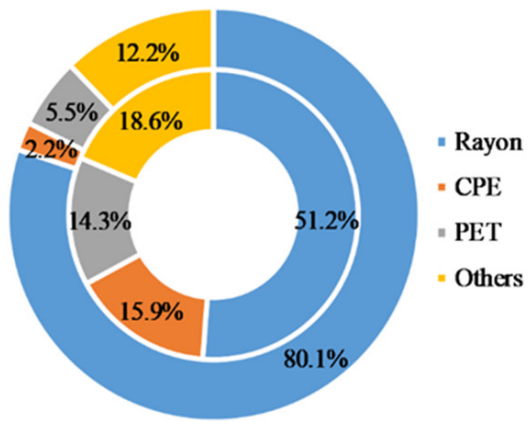

(d) Color

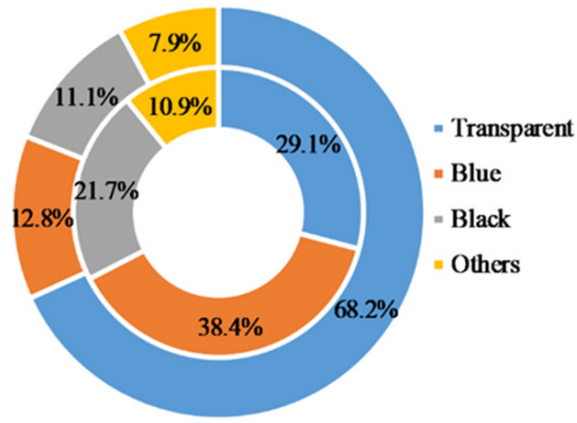

Figure 3. MPs' characteristics in the effluent from WWTPs in Qingdao, China: (a) shape; (b) polymer types; (c) size distribution; (d) color. Inner ring shows the effluent in winter; outer ring shows the effluent in summer.

\subsection{Abundance of MPs in the Effluent from WWTPs}

From Table 1 and Figure 4, it can be seen that the seasonal variation of rayon was more obvious than that of the other polymer type MPs between winter and summer. In most of the previous studies, rayon was considered as a semi-synthetic and not included in the scope of MPs because of the similarity of its spectrum to that of natural cotton [26]. Therefore, rayon and the other polymer types were considered separately in this study. The results are shown in Table 1 and Figure 4 . Rayon abundances in the effluent from the five WWTPs ranged from 4.1 items/L to 19.9 items/L with $12.3 \pm 5.6$ items/L being the average value in winter, and from 33.3 items/L to 116.7 items/L with $67.6 \pm 30.6$ as the average value in summer. As for the other polymer type MPs except rayon, the abundances varied in the ranged of 7.2 19.7 items/L with $12.7 \pm 4.7 \mathrm{items} / \mathrm{L}$ as the average value in winter, and 12.0 20.0 items/L with $16.8 \pm 3.2$ items/L being the average value in summertime. The significant difference existed in the abundances of rayon between two seasons ( $t$-test, $p=0.021$ ), while there was no significant difference in the abundances of MPs except rayon between two seasons ( $t$-test, $p=0.19)$.

\subsection{Emission of MPs in the Effluent Discharged from WWTPS}

The average diameter of fibers was about $30 \mu \mathrm{m}$, as calculated from the 30 measured fibers, and the thickness of fragments was about $3 \mu \mathrm{m}$. Based on the abundance of MPs in each WWTP and their treatment capacities, combining the polymer type and its density, the average size of each type of MPs, the amounts, and masses of MPs discharged into near sea area were estimated. The results are as shown in Table 1 and Figure 4. The daily discharged rayon in the effluent from the five WWTPs varied from $3.3 \times 10^{8}$ to $3.2 \times 10^{9}$ items $/ \mathrm{d}$, equivalent to $0.2 \sim 3.3 \mathrm{~kg}$ in winter. In summer, the corresponding values increased to $3.3 \times 10^{9} \sim 14.9 \times 10^{9}$ items $/ \mathrm{d}(1.8 \sim 10.1 \mathrm{~kg})$. The amount of the other polymer type MPs discharged in the effluent from the WWTPs varied in the range of 
$0.8 \times 10^{9} \sim 2.8 \times 10^{9}$ items $/ \mathrm{d}(0.9 \sim 2.7 \mathrm{~kg} / \mathrm{d})$ in winter and $1.0 \times 10^{9} \sim 3.2 \times 10^{9}$ items $/ \mathrm{d}$ (equivalent to $0.8 \sim 1.7 \mathrm{~kg} / \mathrm{d}$ ) in summer, with the value observed in W2 being the lowest in both winter and summer. The daily discharge of rayon can reach about $8.4 \times 10^{9} \sim 4.25$ $\times 10^{10}$ items from the five WWTPs, which is equivalent to $9.2 \sim 27.8 \mathrm{~kg}$ rayon in mass. The values for the other polymer type MPs ranged from $8.0 \times 10^{9} \sim 11.2 \times 10^{9}$ items, corresponding to $7.6 \sim 5.3 \mathrm{~kg}$ MPs in mass. Considering the resident population in the urban area of Qingdao was 2.74 million in 2019, the rayon per capita daily emission was estimated to be $3.1 \times 10^{3} \sim 1.6 \times 10^{4}$ items/d corresponding to $3.3 \times 10^{-3} \sim 1.0 \times 10^{-2} \mathrm{~g}$, and the per capita daily emission of the other polymer type MPs varied between $2.9 \times 10^{3} \sim 4.1 \times 10^{3}$ items, which is equal to $2.8 \times 10^{-3} \sim 1.9 \times 10^{-3} \mathrm{~g}$.

Table 1. The abundance in the effluent and the emission of rayon and the other polymer type MPs with the effluent from WWTPs in Qingdao, China.

\begin{tabular}{|c|c|c|c|c|c|c|c|c|}
\hline \multirow{3}{*}{ WWTP } & \multirow{3}{*}{$\begin{array}{c}\text { Treat } \\
\text { Capacity } \\
\left(\times 10^{5} \mathrm{M}^{3} / \mathrm{d}\right)\end{array}$} & \multirow{3}{*}{ Season } & \multirow{2}{*}{\multicolumn{2}{|c|}{$\begin{array}{c}\text { Abundance } \\
\text { (Items/L) }\end{array}$}} & \multicolumn{4}{|c|}{ Emission } \\
\hline & & & & & \multicolumn{2}{|c|}{$\times 10^{9}$ Items $/ \mathrm{d}$} & \multicolumn{2}{|c|}{$\mathrm{Kg} / \mathrm{d}$} \\
\hline & & & Rayon & MPs & Rayon & MPs & Rayon & MPs \\
\hline \multirow{2}{*}{1} & \multirow{2}{*}{1.7} & Winter & 7.8 & 7.2 & 1.3 & 1.2 & 1.5 & 1.5 \\
\hline & & Summer & 87.3 & 18.7 & 14.9 & 3.2 & 10.1 & 1.0 \\
\hline \multirow{2}{*}{2} & \multirow{2}{*}{0.8} & Winter & 4.1 & 10.1 & 0.3 & 0.8 & 0.2 & 0.9 \\
\hline & & Summer & 116.7 & 12.0 & 9.3 & 1.0 & 7.5 & 0.8 \\
\hline \multirow{2}{*}{3} & \multirow{2}{*}{1.6} & Winter & 19.9 & 9.6 & 3.2 & 1.5 & 3.3 & 1.6 \\
\hline & & Summer & 43.3 & 20.0 & 6.9 & 3.2 & 2.8 & 1.7 \\
\hline \multirow{2}{*}{4} & \multirow{2}{*}{1.0} & Winter & 15.1 & 16.9 & 1.5 & 1.7 & 1.4 & 1.2 \\
\hline & & Summer & 33.3 & 19.3 & 3.3 & 1.9 & 1.8 & 0.9 \\
\hline \multirow[b]{2}{*}{5} & \multirow[b]{2}{*}{1.4} & Winter & 14.5 & 19.7 & 2.0 & 2.8 & 2.8 & 2.3 \\
\hline & & Summer & 57.3 & 14.0 & 8.0 & 2.0 & 5.7 & 1.0 \\
\hline \multirow[t]{2}{*}{ Sum } & \multirow[t]{2}{*}{6.5} & Winter & $\begin{array}{l}12.3 * \\
( \pm 5.6)\end{array}$ & $\begin{array}{l}12.7 * \\
( \pm 4.7)\end{array}$ & 8.4 & 8.0 & 9.2 & 7.6 \\
\hline & & Summer & $\begin{array}{c}67.6^{*} \\
( \pm 30.6)\end{array}$ & $\begin{array}{l}16.8^{*} \\
( \pm 3.2)\end{array}$ & 42.5 & 11.2 & 27.8 & 5.3 \\
\hline
\end{tabular}

${ }^{*}$ Average value ( \pm std).
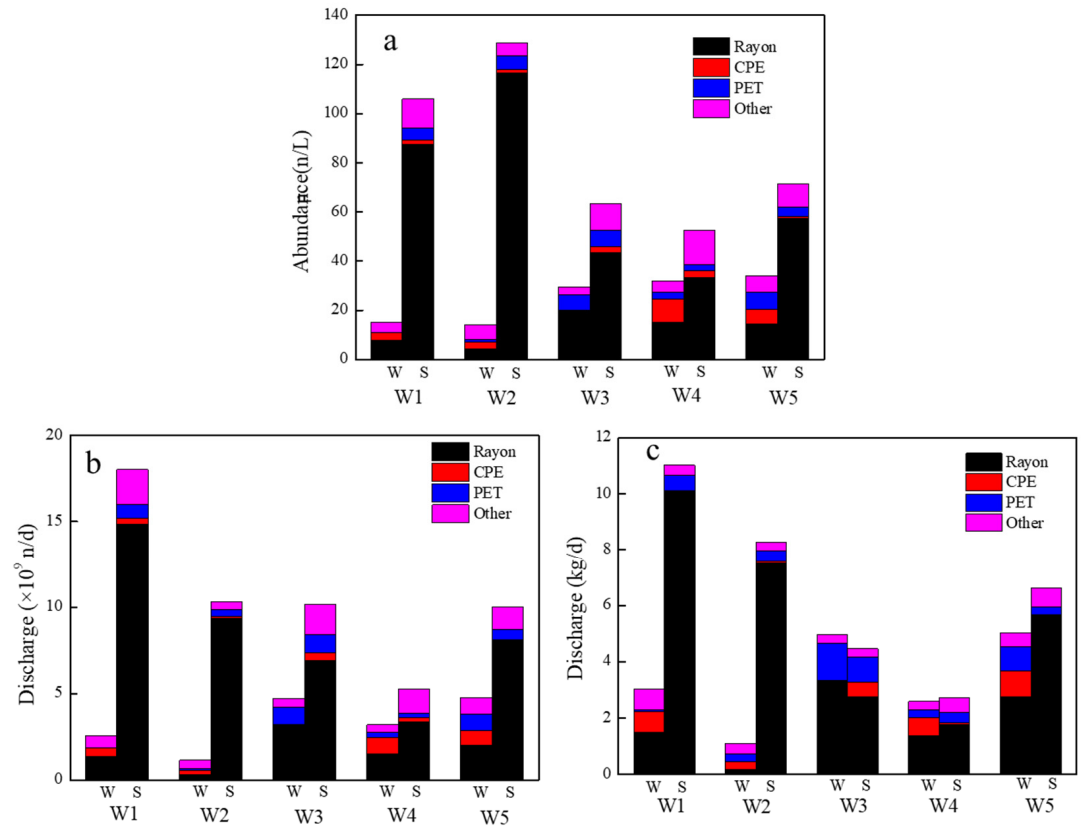

Figure 4. The abundance and emission of MPs in the effluent discharged from WWTPs in winter and summer in Qingdao, China, in which (a) is abundance, (b) emission in items/d, and (c) emission in $\mathrm{kg} / \mathrm{d}$. 


\section{Discussion}

\subsection{Characteristics of MPs in the Effluent of WWTPs in Different Regions}

The various sources and treatment processes of wastewater in WWTPs in different regions may cause discrepancies in the characteristics of MPs in WWTPs. Table 2 shows the characteristics of MPs in the effluent from WWTPs in different regions. It can be seen that there are apparent variations in MPs' characteristics in different regions. In this study, only fiber and fragments MPs were detected, with fibers accounting for more than 95\% of MPs. The Presence of fibers in the effluent was due to their passing through rapid sand filters or membranes longitudinally during the treatment processes [27]. Fibers are predominant in the effluent from WWTPs not only in different cities in China, such as Xi'an, Guilin, and Beijing [23-25], but also in Italy and Australia [27,28]. High proportions of fiber might also be caused by the higher removal rate of fragments and films than fibers in the pretreatment process $[16,17,24]$. The source of fibers is very likely from the laundry process of clothes and garments [20,21]. About 100 fibers in 1 L of laundry sewage and $18,000,000$ synthetic microfibers will be released through laundry for a reference load of $6 \mathrm{~kg}$ of synthetic fibers $[20,29]$. Fragment was only a small part of all MPs in this study. However, in some cases, fragments were also the dominant MPs in the effluent from WWTPs, such as in Scotland and Spain [16,30]. Fragments may come from plastic bags, discarded packaging, and plastic bottles that are widely used in daily life [5]. No microbeads were found in effluent from WWTPs in this study, which was consistent with the results in Beijing and Guilin in China [23,25], while microbeads were the dominant MPs' shapes in effluent of WWTPs in Daegu, South Korea [31].

Rayon was dominant and PET was also usually observed in this study, with the average proportion of $71.7 \%$ and $10.0 \%$, respectively. Xu et al. (2019) also reported that rayon and PET took large proportions (43.45\% and $29.22 \%$, respectively) in the effluents from 11 WWTPs in Changzhou, China [32], while in most of the previous reports, rayon was not considered as MPs because its spectrum is similar to that of natural cotton [26]. Even though it is made by chemical alteration of natural cellulose or fiber structures, rayon fibers have a high surface area due to their long length in relation to the diameter, which may change their physical properties. Therefore, they may affect the floating properties of the material and also act as a carrier for other pollutants [33]. At this moment, behaviors of semi-synthetic MPs in the complex marine environment are not really well understood; thus, all possibilities must be taken into account. PET was a main type of MPs in the effluent from WWTPs in Beijing, China [23], and Australia [28]. Rayon and PET are widely used in apparel production as textile materials and their fibers are often detected in wastewater contributed from washing machines [24]. PET is also frequently used for packaging and may come from water bottles and as a common component of transparent fragments. Only 1 and 20 PP, 1 and 4 PE MPs were observed in winter and summer samples, respectively, in this study. However, PP and PE were the main MPs' materials in WWTPs in Xiamen and $X^{\prime}$ 'an, in China $[18,24]$. The MPs' types were different in the effluent samples in WWTPs in Korea, in which PP was the most dominant MPs (63.3\%) followed by PE and PET (13.8\% and $13.3 \%$, respectively) [19]. The difference may be related to the usage pattern of plastics in different regions. 
Table 2. Comparison of characteristics, abundance, and emission of MPs in the effluent from WWTPs in different regions.

\begin{tabular}{|c|c|c|c|c|c|c|c|c|}
\hline Location & $\begin{array}{l}\text { Sampling Smallest Mesh } \\
\text { Size or Filters }(\mu \mathrm{m})\end{array}$ & Main Shape & $\begin{array}{c}\text { Main Polymer } \\
\text { Type }\end{array}$ & $\underset{(\mu \mathrm{m})}{\operatorname{Dominant} \text { Size }}$ & Main Colors & $\begin{array}{c}\text { Abundance } \\
\text { (Items/L) }\end{array}$ & $\begin{array}{l}\text { Discharge } \\
\text { (Items/d) }\end{array}$ & Reference \\
\hline Scotland & 65 & Flakes and fibers & $\begin{array}{l}\text { Polyester, } \\
\text { polyamide }\end{array}$ & - & Red, blue, and green & $0.28 \sim 1.54$ & $3.6 \times 10^{6} \sim 4.6 \times 10^{8}$ & [16] \\
\hline Italy & 63 & Line and films & $\begin{array}{l}\text { Polyesters, } \\
\text { polyamide }\end{array}$ & $100 \sim 500$ & - & $0.4 \pm 0.1$ & $1.6 \times 10^{8}$ & [27] \\
\hline Australia & 25 & Fiber & PET, PE & - & $\begin{array}{l}\text { White and } \\
\text { transparent }\end{array}$ & $0.25 \pm 0.04$ & $6.5( \pm 1.1) \times 10^{7}$ & [28] \\
\hline Spain & 25 & Fragments & polyesters & 25 104 & $\begin{array}{l}\text { White and } \\
\text { transparent }\end{array}$ & $12.8 \pm 6.3$ & $3 \times 10^{9}$ & [30] \\
\hline Korea & 1.2 & Microbeads & - & - & - & $33 \sim 297$ & $8.8 \times 10^{8} \sim 1.39 \times 10^{11}$ & [31] \\
\hline Xiamen, China & 43 & $\begin{array}{l}\text { Granule, } \\
\text { fragments }\end{array}$ & $\mathrm{PP}, \mathrm{PE}$ & $125 \sim 355$ & White, clear & $0.20 \sim 1.37$ & $6.5 \times 10^{8}$ & [18] \\
\hline Beijing, China & 50 & Fibers & PET, PS, PP & $<1000$ & $\begin{array}{l}\text { Black, transparent, } \\
\text { blue }\end{array}$ & $0.59 \pm 0.22$ & $0.59 \pm 0.22 \times 10^{9}$ & [23] \\
\hline Xi'an, China & 75 & Fiber & PP, PE, PS & $<500$ & $\begin{array}{c}\text { Transparent and } \\
\text { black }\end{array}$ & $22.9 \pm 7.2$ & $3.4 \times 10^{9}$ & [24] \\
\hline Qingdao, China & 0.45 & Fiber & Rayon, PET & $<1000$ & transparent & $\begin{array}{c}12.3 \pm 5.6^{\mathrm{Ra}} \\
67.6 \pm 306^{\mathrm{Rb}} \\
12.7 \pm 4.7^{\mathrm{a}} \\
16.8 \pm 3.2^{\mathrm{b}}\end{array}$ & $\begin{array}{l}8.4 \sim 42.5 \times 10^{9 \mathrm{R}} \\
8.0 \sim 11.2 \times 10^{9 \mathrm{O}}\end{array}$ & This study \\
\hline
\end{tabular}

Ra: average value of rayon in winter; Rb: average value rayon in summer; a: average value of the other polymer type MPs in winter; b: average value of the other polymer type MPs in summer; R: rayon; O: the other polymer type MPs. 
The color of MPs was not considered or reported in some reports [17,24,27,30,31]. This may relate to the changing of color caused by photo bleaching or oxidation during the usage and treatment processes in WWTPs. However, no significant difference was observed in color diversity of MPs in the influent and effluent from WWTPs in Xiamen, which suggested that wastewater treatment processes play a minor role in changing the MPs' colors [18]. The transparent, blue, and black MPs accounted for $56.9 \%, 20.2 \%$, and $14.1 \%$ of the total MPs, respectively, in this study. The white and clear MPs accounted for $55.1 \%$ and $50.3 \%$ of the total MPs in the influent and effluent of WWTPs in Xiamen, China [18]. The majority of MPs were black (36.60\%), transparent $(33.84 \%)$, and blue $(11.88 \%)$ in the effluent of WWTPs in Beijing, suggesting the color of MPs is highly location specific [23].

\subsection{The Abundance and Emission of MPs from Other WWTPS}

MPs' content in the influent and effluent from WWTPs may vary with difference in the sources of wastewater, service population and area, the tertiary industry in the service area, the treatment process, and operation conditions of WWTPs [24]. An overview of previous reported MPs' abundance in different regions is summarized in Table 2. The MPs' abundance except rayon in this study was one to two orders of magnitude higher than those in Scotland [16], Italy [27], Australia [29], and Xiamen [18] and Beijing [23] in China. However, it was in the same level as those in Xi'an city, China [24], and Spain [30], and less than that in Korea (33 297 items/L) [31]. The different sampling volumes, screen meshes of different pore sizes, and the filter apertures may also play an important role on the content of MPs in WWTPs [17,34].

Abundances of MPs were higher by approximately one order of magnitude when filtered through a 20- $\mu \mathrm{m}$-pore size compared to a $250-\mu \mathrm{m}$ size [25]. It was reported that the number of MPs increased with decreasing of the size in WWTPs in Korea, followed the power law [19]. The $0.45-\mu \mathrm{m}$-pore size filter used in this study led to a relatively higher MPs' abundance caused by retaining more small fibers.

Although WWTPs have high MPs' removal rates, as previously reported [24,25,27,31], the effluents still discharged a large amount of MPs to the environment considering the huge volume of wastewater. The emission of MPs from WWTPs in several cities in previous reports are also listed in Table 2. The amounts of MPs except rayon discharged from WWTPs in this study were also about one to three orders of magnitude higher than those in Scotland [16], Italy [27], Australia [28], and Xiamen and Beijing [23] in China [18], while the emission from WWTPs in Spain [30] and in Xi'an, China [24], were in the same ranges with the values of MPs except rayon in this study. The daily discharges of MPs from WWTPs in Korea were much higher than those in this study [31]. The difference among the values of MPs' emission from WWTPs in different regions were similar to that of the abundance. This indicated that the relatively higher MPs' abundance caused by a discrepancy in the sampling method pretreatment processes among the studies was a primary reason leading to the corresponding higher emission of MPs in this study. The variation of treatment capacity in different WWTPs is also an impact factor on the difference of the MPs' emission.

In this study, the mass of MPs except rayon discharged from the five WWTPs into Jiaozhou Bay and nearshore area was estimated as $5.3 \sim 7.6 \mathrm{~kg}$, which is equivalent to $1.9 \times 10^{-3 \sim} 2.8 \times 10^{-3} \mathrm{~g} /($ capita d). This result is about 1.3 1.8 times of that in Danish, where it was only $0.56 \mathrm{~g} \mathrm{MP} /$ (capita year) [34]. This difference may relate to that only the MPs in the size of 10 500 $\mu \mathrm{m}$ were considered, and the fiber volume was calculated presuming a cylindrical shape with $40 \%$ void fraction in that report [34], while in our study, all sizes of MPs except rayon polymer and no void fraction were considered.

\subsection{The Difference of MPs' Characteristics in the Effluent from WWTPs between Winter and Summer}

In this study, fragments were more often observed in summer than in winter. Rayon fibers were dominant in both summer and in winter, with a higher percentage in summer. 
MPs smaller than $500 \mu \mathrm{m}$ were $35.7 \%$ in winter and increased to $56.7 \%$ in summer, indicating more small-sized MPs were observed and resulting in the smaller average size of MPs in summer. It is possible that the large-size $(1000 \sim 5000 \mu \mathrm{m})$ MPs tended to break and cause the small-size $(0 \sim 1000 \mu \mathrm{m})$ MPs increasing in winter [25]. Transparent MPs with a percentage of $65.8 \%$ were predominant in summer. This is very likely the result of a high frequency of clothes washing and more light color clothing in the summertime. It was reported that about $93 \%$ of microfibers were smaller than $500 \mu \mathrm{m}$ in the washing wastewater [29].

When comparing the variations of abundances, numbers, and masses discharged from WWTPs between winter and summer, the mass of rayon varied in a narrow scope than those in abundances and numbers. Summer data of rayon, both the average value of abundances and the sum of items, were about 5 times higher than those in winter, while the mass of rayon in the effluent discharged from WWTPs in summer were only 3 times of that in winter. However, as for the data of the other polymer type MPs, they were only 30 40\% higher in summer than in winter for the values of abundance and the sum of numbers. The total mass of the other polymer type MPs was only $70 \%$ of that in summer, which is converse with their numbers. This indicates that more small size MPs were discharged from WWTPs in summer than those in winter. The seasonal variation of MPs in this study was mainly caused by that of rayon. It is probably related to the high washing frequency in summer, which may be affected by the high washing frequency of local people. As one of famous tourist cities in China, there were about $1.11 \times 10^{8}$ person-times visits to Qingdao in 2019, and most of them were from May to October. The tourism activities, such as associated catering accommodations, also play an important role in affecting the total emission of MPs, especially rayon fiber, with smaller than $500 \mu \mathrm{m}$ part as the dominant part $[25,29]$.

Our results indicated that the seasonal variations in the characteristics of MPs between winter and summer were mainly caused by that of rayon. An overestimation of emission of MPs from WWTPs would occur if the abundance of MPs in this study was calculated solely from the data obtained in summer, which were consistent with that in Changjiang Estuary area [26]. Both the number and mass of MPs should be considered when evaluating the discharge of MPs from WWTPs. Xu et al. (2019) also found that high particle numbers do not necessarily mean that MP is a significant contributor to the total amount of suspended solids in raw wastewater as a high particle number is not associated with high particle mass [32].

\subsection{The contribution of MPs from WWTPs to Jiaozhou Bay, China}

The effluents from W1 W4 in this study discharged directly into Jiaozhou Bay. It was reported that PET and PP were the main polymer types in both seawater and sediment in Jiaozhou Bay, and five polymer types (PET, PP, PE, PVC, and rayon) were detected in the water and the sediment samples from the estuaries, with a higher percentage of rayon in water than those in sediments, indicating the potential settlement of rayon at estuary areas [35]. This may be related to the settlement of rayon in the estuary area due to its high density $\left(1.5 \mathrm{~g} / \mathrm{cm}^{-3}\right)$ than in seawater [36]. The proportion of fiber MPs was $77.14 \%$ in the seawater in Jiaozhou Bay, with an average size of $1.41 \pm 0.74 \mathrm{~mm}$. The abundance of MPs in the seawater and estuary water of Jiaozhou Bay were 1 6 items /50L and 7.5 \pm 4.4 items /50 L, respectively [35], which was lower than those in the effluents from WWTPs. About $6.4 \times 10^{9} \sim 3.4 \times 10^{10} \mathrm{items} / \mathrm{d}(6.4 \sim 22.1 \mathrm{~kg} / \mathrm{d})$ rayon and $5.3 \times 10^{9} \sim 9.3 \times 10^{9}$ items / d (equivalent to $5.3 \mathrm{~kg} / \mathrm{d} \sim 4.4 \mathrm{~kg} / \mathrm{d}$ ) of the other MPs except rayon were discharged from W1 W4 into Jiaozhou Bay. Thus, the WWTPs can be considered as one of the sources of MPs, which is consistent with previous reports [16,17].

\section{Conclusions}

The characteristics of MPs in the effluent from the five WWTPs in Qingdao in winter and summer were investigated. The results showed that fibers were the main fraction. Micro-FTIR analysis indicated that rayon, PET, and CPE were the predominant polymer 
types. MPs smaller than $2000 \mu \mathrm{m}$ were dominant in the effluent of WWTPs, and the average size of MPs was $1010 \pm 924 \mu \mathrm{m}$ and $610 \pm 591 \mu \mathrm{m}$ in winter and summer, respectively. The seasonal variation of MPs' characteristics in the effluent was mainly caused by that of rayon, which may be affected by the living habits of local people and tourism activities. Based on the abundance, size, polymer type, and treatment capacity of WWTPs, the daily discharge of rayon and the other polymer type MPs can reach about $8.4 \times 10^{9} \sim 42.5 \times 10^{9}$ items and $8.0 \times 10^{9} \sim 11.2 \times 10^{9}$ items, corresponding to $9.2 \sim 27.8 \mathrm{~kg}$ rayon and $7.6 \sim 5.3 \mathrm{~kg}$ the other polymer type MPs in mass, respectively. When assessing the discharge of MPs from WWTPs, it is essential to consider both number and mass of MPs. Though the actual abundance of MPs is highly dependent on the sampling and analytical method, our results indicate that the WWTPs may be one of the important sources of MPs in Jiaozhou Bay and near shore areas.

Author Contributions: F.J.: Conceptualization, resource, writing-original draft preparation, review and editing; M.W.: methodology, visualization, and analysis; J.D.: data curation, validation, Supervision; W.C.: data curation and analysis, software; C.S.: writing-review and editing. All authors have read and agreed to the published version of the manuscript.

Funding: This research was funded by the investigation and Evaluation of Microplastics in Seawater (ZY0721004) Basic Scientific Fund for National Public Research Institutes of China (2020Q10) and the Asian Countries Maritime Cooperation Fund (99950410). We also thank the support from the Construction and Operation of Test and Technical Support System for Natural Resources Investigation and Evaluation.

Institutional Review Board Statement: Not applicable.

Informed Consent Statement: Not applicable.

Data Availability Statement: Not applicable.

Acknowledgments: We thank Yi Sun from Qingdao Municipality on urban drainage monitoring station for help in the sample collection.

Conflicts of Interest: Not applicable.

\section{References}

1. Law, K.L.; Thompson, R.C. Microplastics in the seas. Science 2014, 345, 6193. [CrossRef]

2. Dris, R.; Gasperi, J.; Mirande, C.; Mandin, C.; Guerrouache, M.; Langlois, V.; Tassin, B. A first overview of textile fibers, including microplastics, in indoor and outdoor environments. Environ. Pollut. 2017, 221, 453-458. [CrossRef]

3. Zhang, L.; Xie, Y.; Liu, J.; Zhong, S.; Qlan, Y.; Gao, P. An overlooked entry pathway of microplastics into agricultural soils from application of sludge based fertilizers. Environ. Sci. Technol. 2020, 54, 4248-4255. [CrossRef]

4. Zhang, K.; Su, J.; Xiong, X.; Wu, X.; Wu, C.; Liu, J. Microplastic pollution of lakeshore sediments from remote lakes in Tibet plateau, China. Environ. Pollut. 2016, 219, 450-455. [CrossRef]

5. Mani, T.; Hauk, A.; Walter, U.; Burkhardt-Holm, P. Microplastics profile along the Rhine river. Sci. Rep. 2015, 5, 1-7. [CrossRef]

6. Mu, J.; Zhang, S.; Qu, L.; Jin, F.; Fang, C.; Ma, X.; Zhang, W.; Wang, J. Microplastics abundance and characteristics in surface waters from the Northwest Pacific, the Bering Sea, and the Chukchi Sea. Mar. Pollut. Bull. 2019, 143, 58-65. [CrossRef]

7. Waller, C.L.; Griffiths, H.J.; Waluda, C.M.; Thorpe, S.E.; Loaiza, I.; Moreno, B.; Pacherres, O.; Hughes, K.A. Microplastics in the Antarctic marine system: An emerging area of research. Sci. Total Environ. 2017, 598, 220-227. [CrossRef]

8. Van Cauwenberghe, L.; Vanreusel, A.; Mees, J.; Janssen, C.R. Microplastic pollution in deep-sea sediments. Environ. Pollut. 2013, 182, 495-499. [CrossRef]

9. Cau, A.; Avio, C.; Dessi, C.; Moccia, D.; Pusceddu, A.; Regoli, F.; Cannas, R.; Follesa, M.C. Benthic crustacean digestion can modulate environmental fate of microplastics in the deep sea. Environ. Sci. Technol. 2020, 54, 4886-4892. [CrossRef]

10. Barnes, D.K.A.; Galgani, F.; Thompson, R.C.; Barlaz, M. Accumulation and fragmentation of plastic debris in global environments. Philos. Trans. R. Soc. Lond. B Biol. 2009, 364, 1985-1998. [CrossRef]

11. Ziajahromi, S.; Kumar, A.; Neale, P.A.; Leusch, F.D.L. Impact of microplastic beads and fibers on waterflea (Ceriodaphnia dubia) survival, growth, and reproduction: Implications of single and mixture exposures. Environ. Sci. Technol. 2017, 51, 13397-13406. [CrossRef]

12. Engler, R.E. The complex interaction between marine debris and toxic chemicals in the ocean. Environ. Sci. Technol. 2012, 46, 12302-12315. [CrossRef]

13. Avio, C.G.; Gorbi, S.; Milan, M.; Benedetti, M.; Fattorini, D.; d'Errico, G.; Pauletto, M.; Bargelloni, L.; Reqoli, F. Pollutants bioavailability and toxicological risk from microplastics to marine mussels. Environ. Pollut. 2015, 198, 211-222. [CrossRef] 
14. Schymanski, D.; Goldbeck, C.; Humpf, H.U.; Fürst, P. Analysis of microplastics in water by micro-Raman spectroscopy: Release of plastic particles from different packaging into mineral water. Water Res. 2018, 129, 154-162. [CrossRef]

15. Ding, J.; Li, J.; Sun, C.; Jiang, F.; He, C.; Zhang, M.; Ju, P.; Ding, N. An examination of the occurrence and potential risks of microplastics across various shellfish. Sci. Total Environ. 2020, 739, 139887. [CrossRef]

16. Murphy, F.; Ewins, C.; Carbonnier, F.; Quinn, B. Wastewater Treatment Works (WwTW) as a Source of Microplastics in the Aquatic Environment. Environ. Sci. Technol. 2016, 50, 5800-5808. [CrossRef]

17. Talvitie, J.; Mikola, A.; Koistinen, A.; Setälä, O. Solutions to microplastic pollution-removal of microplastics from wastewater effluent with advanced wastewater treatment technologies. Water Res. 2017, 123, 401-407. [CrossRef]

18. Long, Z.; Pan, Z.; Wang, W.; Ren, J.; Yu, X.; Lin, L.; Lin, H.; Chen, H.; Jin, X. Microplastic abundance, characteristics, and removal in wastewater treatment plants in a coastal city of China. Water Res. 2019, 155, 255-265. [CrossRef]

19. Park, H.; Oh, M.J.; Kim, P.G.; Kim, G.; Jeong, D.H.; Ju, B.K.; Lee, W.S.; Chung, H.M.; Kang, H.J.; Kwon, J.H. National reconnaissance survey of microplastics in municipal wastewater treatment plants in Korea. Environ. Sci. Technol. 2020, 54, 1503-1512. [CrossRef]

20. Browne, M.A.; Crump, P.; Niven, S.J.; Teuten, E.; Tonkin, A.; Galloway, T.; Thompson, R. Accumulation of microplastic on shorelines worldwide: Sources and sinks. Environ. Sci. Technol. 2011, 45, 9175-9179. [CrossRef]

21. Napper, I.E.; Thompson, R.C. Release of synthetic microplastic plastic fibres from domestic washing machines: Effects of fabric type and washing conditions. Mar. Pollut. Bull. 2016, 112, 39-45. [CrossRef]

22. Napper, I.E.; Bakir, A.; Rowland, S.J.; Thompson, R.C. Characterisation, quantity and sorptive properties of microplastics extracted from cosmetics. Mar. Pollut. Bull. 2015, 99, 178-185. [CrossRef]

23. Yang, L.; Li, K.; Cui, S.; Kang, Y.; An, L.; Lei, K. Removal of microplastics in municipal sewage from China's largest water reclamation plant. Water Res. 2019, 155, 175-181. [CrossRef]

24. Yang, Z.; Li, S.; Ma, S.; Liu, P.; Peng, D.; Ouyang, Z.; Guo, X. Characteristics and removal efficiency of microplastics in sewage treatment plant of Xi'an City, Northwest China. Sci. Total Environ. 2021, 771, 145377. [CrossRef]

25. Zhang, L.; Liu, J.; Xie, Y.; Zhong, S.; Gao, P. Occurrence and removal of microplastics from wastewater treatment plants in a typical tourist city in China. J. Clean. Prod. 2021, 291, 125968. [CrossRef]

26. Zhao, S.; Wang, T.; Zhu, L.; Xu, P.; Wang, X.; Gao, L.; Li, D. Analysis of suspended microplastics in the Changjiang Estuary: Implications for riverine plastic load to the ocean. Water Res. 2019, 161, 560-569. [CrossRef]

27. Magni, S.; Binelli, A.; Pittura, L.; Avio, C.G.; Torre, C.D.; Parenti, C.C.; Gorbi, S.; Regoli, F. The fate of microplastics in an Italian Wastewater Treatment Plant. Sci. Total Environ. 2019, 652, 602-610. [CrossRef]

28. Ziajahromi, S.; Neale, P.A.; Rintoul, L.; Leusch, F.D.L. Wastewater treatment plants as a pathway for microplastics: Development of a new approach to sample wastewater-based microplastics. Water Res. 2017, 112, 93-99. [CrossRef]

29. Galvão, A.; Aleixo, M.; De, P.H.; Lopes, C.; Raimundo, J. Microplastics in wastewater: Microfiber emissions from common household laundry. Environ. Sci. Pollut. Res. 2020, 27, 26643-26649. [CrossRef]

30. Edo, C.; González-Pleiter, M.; Leganés, F.; Fernández-Piñas, F.; Rosal, R. Fate of microplastics in wastewater treatment plants and their environmental dispersion with effluent and sludge. Environ. Pollut. 2020, 259, 113837. [CrossRef]

31. Hidayaturrahman, H.; Lee, T.G. A study on characteristics of microplastic in wastewater of South Korea: Identification, quantification, and fate of microplastics during treatment process. Mar. Pollut. Bull. 2019, 146, 696-702. [CrossRef]

32. Xu, X.; Jian, Y.; Xue, Y.G.; Hou, Q.T.; Wang, L.P. Microplastics in the wastewater treatment plants (WWTPs): Occurrence and removal. Chemosphere 2019, 235, 1089-1096. [CrossRef]

33. Steinmann, W.; Saelhoff, A.K. Essential Properties of Fibres for Composite Applications. In Fibrous and Textile Materials for Composite Applications; Rana, S., Fangueiro, R., Eds.; Springer: Singapore, 2016; pp. 39-73.

34. Simon, M.; van Alst, N.; Vollertsen, J. Quantification of microplastic mass and removal rates at wastewater treatment plants applying Focal Plane Array (FPA)-based Fourier Transform Infrared (FT-IR) imaging. Water Res. 2018, 142, 1-9. [CrossRef]

35. Zheng, Y.; Li, J.; Cao, W.; Liu, X.; Jiang, F.; Ding, J.; Yin, X.; Sun, C. Distribution characteristics of microplastics in the seawater and sediment: A case study in Jiaozhou Bay, China. Sci. Total Environ. 2019, 674, 27-35. [CrossRef]

36. Gago, J.; Carretero, O.; Filgueiras, A.; Viñas, L. Synthetic microfibers in the marine environment: A review on their occurrence in seawater and sediments. Mar. Pollut. Bull. 2018, 127, 365-376. [CrossRef] 